\title{
Use of the Cam-Clay Model in Finite Element Calculations after Identification of Soils from Simple Mechanical Tests
}

\author{
Cheikhou Ndiaye1, Yves Berthaud², Raphael Catusse ${ }^{2}$ \\ ${ }^{1}$ Laboratory of Mechanics and Modeling-UFR Engineering Sciences, University of Thies, Thies, Senegal \\ ${ }^{2}$ Faculty of Science and Engineering, CNRS, Jean-le-Rond d'Alembert Institute, Sorbonne University, Paris, France \\ Email: cheikhou.ndiaye@univ-thies.sn
}

How to cite this paper: Ndiaye, C., Berthaud, Y. and Catusse, R. (2021) Use of the Cam-Clay Model in Finite Element Calculations after Identification of Soils from Simple Mechanical Tests. Geomaterials, 11, 59-68.

https://doi.org/10.4236/gm.2021.113004

Received: July 1, 2021

Accepted: July 27, 2021

Published: July 30, 2021

Copyright ( 2021 by author(s) and Scientific Research Publishing Inc. This work is licensed under the Creative Commons Attribution International License (CC BY 4.0).

http://creativecommons.org/licenses/by/4.0/

\section{(c) (i) Open Access}

\begin{abstract}
In order to make the use of complex elasto-plastic behavior models more accessible, we attempted to identify the Cam-Clay model in two samples of tropical and lateritic soils (from Senegal/West Africa) from casagrande box shear and oedometric tests. This methodology was used as a substitute for triaxial trials. In this article, we first verify the test results by the finite element method with the Optum software. We use a simulation of the tests with the modified Cam Clay model as the behavior model. Then, we simulate the oedometric test on tropical soils with the Castem software and also use the modified Cam Clay model. These calculations make it possible to write the criterion of plasticity of the material starting from the expression of the surface of load while passing by the calculation of the volumetric and deviatoric stresses.
\end{abstract}

\section{Keywords}

Modelling, Comportment, Elasto-Plasticity, Load Surface, Constraints, Volumetric, Deviatoric, Simulation, Optum, Cast3M, Criteria, Tropical, Lateritic, Soils

\section{Introduction}

The concepts of limit state and critical state proposed by Roscoe, Schofield and Wroth between 1958 and 1968 [1] [2] have been shown to apply well to natural agile, as shown in this illustration by Tavenas [3] in Figure 1.

This identification is repeated for two lateritic soils from Senegal from simple mechanical tests and the results are compared with results from shear tests on samples from the same locality [4] [5] [6]. 


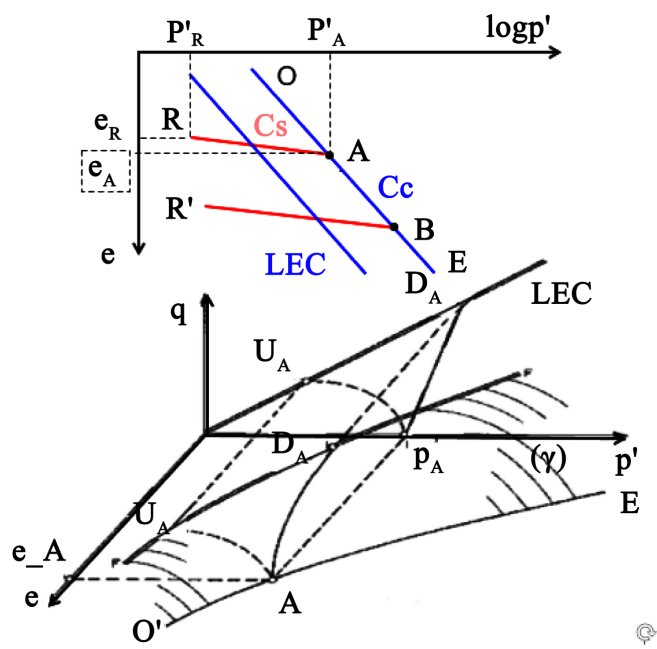

Figure 1. Representation of the model of cam clay in the (e, p, q) and (e, lnp) [3] plans.

Since the purpose of using Cam Clay's model is to correctly describe a loading path, to make an elastoplastic study and to arrive at finite element method calculations, we present in this article the continuation of the study started on the two above-mentioned samples.

For this purpose, a verification study of the tests on Optum G2 [7] was followed by structural calculations using Cast3M [8]. It should be noted that, for the experimental test procedure, the reader is invited to refer to the publication [4].

\section{Verification of the Casagrande's Shear Box Tests}

On OptumG2 [7], Finites Elements calculation software, we verified our mechanical results by simulating the shear and oedometric tests.

Under the hypothesis of plane stresses, the $2 \mathrm{D}$ specimen is modelled by a $60 \times$ $20 \mathrm{~mm}$ rectangle, made of a material to which Cam Clay's modified law is applied. The upper half-box is modelled by a set of rigid plates whose rotation is blocked in order to best approximate the real behavior of the ground during the test (Figure 2).

By a limit analysis for each normal stress, one can plot the evolution of the shear stress $\tau$ as a function of the normal stress $\sigma$ and thus determine the cohesion $\mathrm{c}$ and the internal angle of friction $\varphi$.

The initial conditions of the constituent material have no influence on the limit state of the structure and since the structure is small in size, gravity can be neglected.

The limit analysis runs in two steps in order to approach the actual solution:

1) The calculation of the lower bound: the mesh is made of triangles with three nodes (only one Gauss point for stress integration) allowing the discontinuity of stresses between elements (but not of displacements). This step underestimates the stiffness matrix and allows the calculation of the lower bound of the solution. 


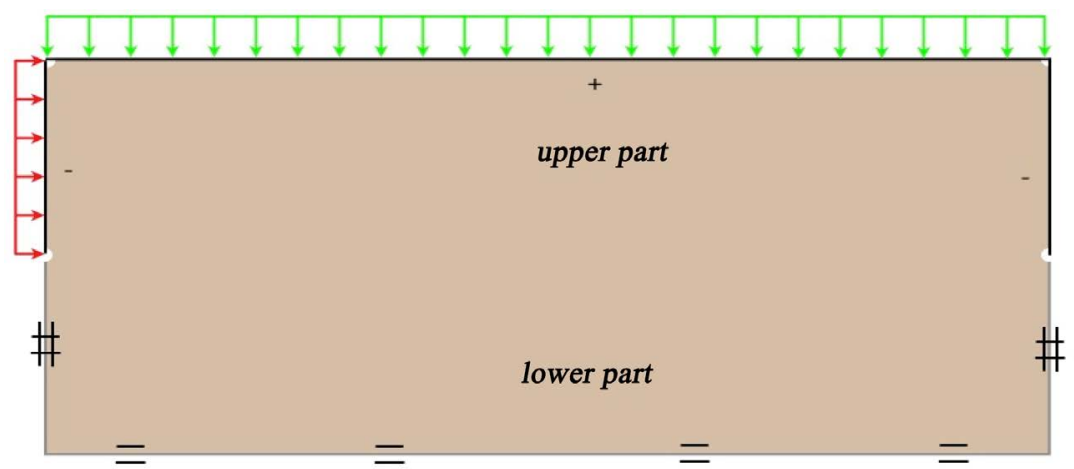

Figure 2. Presentation of the casagrande shear box on Optum G2 with locking system boundary conditions.

2) Calculation of the upper bound: the mesh is made up of triangles with 6 nodes. The 3 Gauss points of these elements have the particularity here of being confused with the vertices of the triangle. Thus the interpolation of the displacements is quadratic, and that of the constraints is linear. They ensure the continuity of constraints and displacements. This step allows to calculate the upper bound of the solution by overestimating the stiffness matrix.

\section{Influence of the Size of the Model}

The size of the Casagrande box does not usually have influence on the test results [9]. However, as OptumG2 is designed for calculations on large structures, calculations are faster and more accurate by increasing the size of the model. We present a small comparison in Table 1 .

The values of the shear stresses at specimen vary little for larger scale models, which is why the calculations in this study are performed on a 10 scale model (60 * $20 \mathrm{~cm}$ specimen), in order to best respect the real test conditions $(6 * 2 \mathrm{~cm})$ and to facilitate the resolution of numerical problems.

\subsection{Numerical Results of Shear Box Tests and Comparisons with Experimental Results}

Calculations are performed using the cohesions and friction angles experimentally obtained during tests on the two soils [4]. The names of these samples are: Sindia and Keur Samba (Table 2 and Table 3).

It is clear that the shear stress increases as it converges towards the limit value ( $\tau_{-}$rup), obtained with the limit analysis. Furthermore, the behavior of the sample was first contracting and then expanding. This is a behavior observed in the experimental tests [4]. The mechanical characteristics $(c$ and $\varphi)$ are similar in both cases, even if there are some discrepancies in the cohesion values that are not very noticeable.

\subsection{Numerical Results of Oedometer Tests and Comparisons with Experimental Results}

Taking into account the cell (cylinder of $8 \mathrm{~cm}$ diameter and $2 \mathrm{~cm}$ height), the 
Table 1. Illustrative values of the influence of the size of the model.

\begin{tabular}{ccccc}
\hline Scale & Lower Bound & Upper Bound & Gap max $(\%)$ & Constraint of rupture $(\mathrm{kPa})$ \\
\hline$\times 1$ & 2113.1 & 2185.6 & 3.37 & 358.2 \\
$\times 10$ & 2125 & 2190.4 & 3.03 & 359.6 \\
$\times 50$ & 2159.9 & 2224.5 & 2.95 & 365.4 \\
$\times 100$ & 2195.2 & 2271.6 & 3.42 & 372.2 \\
\hline
\end{tabular}

Table 2. Values of the cohesions and angle of internal friction for the specimen of SINDIA.

\begin{tabular}{ccc}
\hline & $\mathrm{c}(\mathrm{kPa})$ & $\varphi\left({ }^{\circ}\right)$ \\
\hline Experimental & 224 & 42 \\
Numerical & 199 & 39.1 \\
Difference (\%) & 11 & 6.9 \\
\hline
\end{tabular}

Table 3. Values of the cohesions and internal rubbing angle for the sample of Keur Samba.

\begin{tabular}{ccc}
\hline & $c(\mathrm{kPa})$ & $\varphi\left({ }^{\circ}\right)$ \\
\hline Experimental & 264 & 52 \\
Numerical & 217 & 46.2 \\
Difference (\%) & 17.7 & 11.1 \\
\hline
\end{tabular}

material and the load, the sample is modelled axisymmetrically by a $4 \times 2 \mathrm{~cm}^{\wedge} 2$ rectangle.

- On the left edge of the cell, located on the axis of symmetry, normal displacements are blocked.

- On the right edge, glued to the cell wall, normal displacements and flow are blocked.

- On the lower edge, the material is drained and the normal displacements are also blocked.

- At the upper edge, the material is drained and the load is applied by a constant distributed force.

Several elasto-plastic analyses are carried out, corresponding to the different loading levels. From certain vertical stress values effectives a stepwise discharge is performed, in order to obtain loading-unloading curves. Look at the representation in Figure 3.

$\mathrm{Cc}$ (coefficient of compressibility) and Cg (coefficient of swelling) (or $\lambda$ (slope of the isotropic virgin curve)) and $\mathrm{k}$ (slope of the unloading-reloading curve)) are sought by these several elasto-plastic analyses. But first, the influence of friction on the wall can be checked by using the "Reduction Factor" on the Sindia sample, shown at Figure 4.

The friction at the interface with the material is translated by the "Reduction Factor" ( $\mathrm{RF}=1$ corresponding to perfect adhesion, and $\mathrm{RF}=0$ to frictionless 


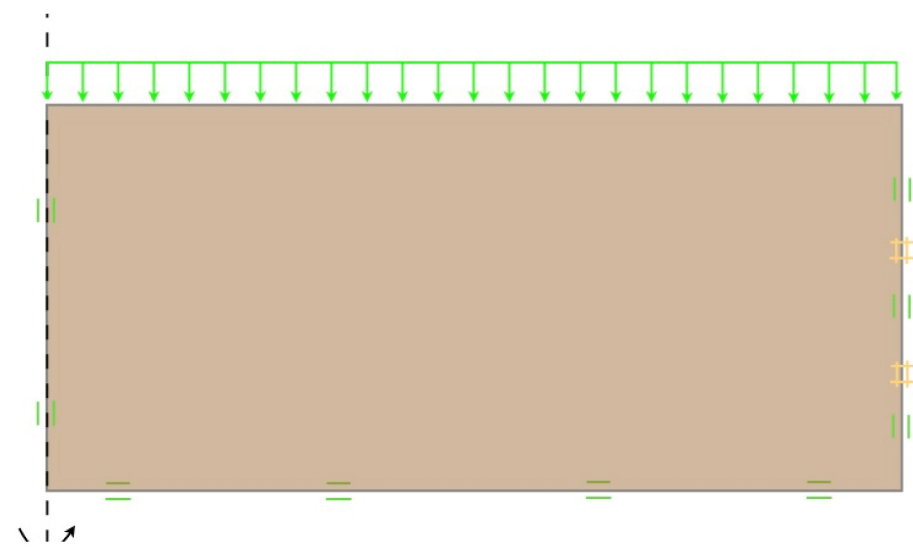

Figure 3. Presentation of the oedometer cell in Optum G2.

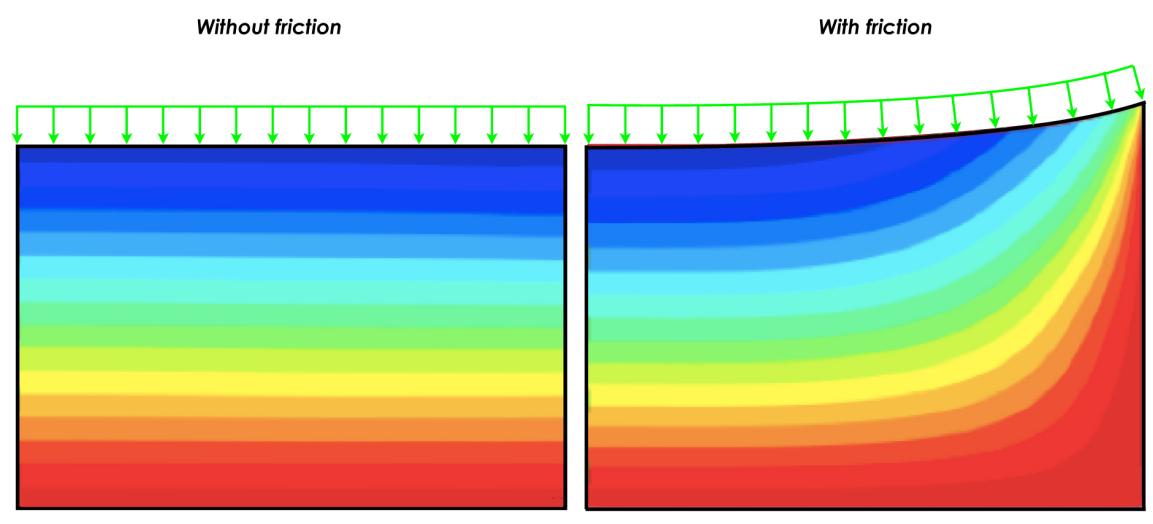

Figure 4. Influence of the friction of the wall, tested on the Sindia specimen.

sliding). In the frictionless case, the vertical displacement is homogeneous over the entire upper edge. Otherwise, an average height variation on the upper edge is calculated by exporting the results of the analysis in Matlab for example. It is noted that the friction is only influent very little on the value of the average displacement on the upper edge. To facilitate the calculations, the elastoplastic analyses were subsequently performed from the model without plates with boundary conditions (equivalent to the model with frictionless plates).

Numerical results compared to laboratory tests are presented in Table 4 and Table 5.

The numerical results obtained are consistent with the experimental results. If significant gaps can be observed for the lateritic Keur Samba sample (Table 5), the orders of magnitude are correct. The results are obtained for much higher stresses than in the actual tests, which is probably due to a much lower initial pre-consolidation stress in the actual sample. The difference between the experiment and the numerical simulation gives a good appreciation of the consistency of the results [10].

\section{Oedometer Test Modelling Using Cast3M}

In these calculations, the elastoplastic model chosen is the modified Cam Clay 
Table 4. Values of the slopes of the virgin and unloading-reloading curves of SINDIA.

\begin{tabular}{ccc}
\hline & 1 & $\mathrm{~K}$ \\
\hline Experimental & 0.05 & 0.004 \\
Numerical & 0.051 & 0.0041 \\
Difference (\%) & 1.86 & 2.5 \\
\hline
\end{tabular}

Table 5. Values of the slopes of the virgin and unloading-reloading curves of Keur Samba.

\begin{tabular}{ccc}
\hline & 1 & $\mathrm{~K}$ \\
\hline Experimental & 0.06 & 0.004 \\
Numerical & 0.054 & 0.0061 \\
Difference (\%) & 10 & 52.5 \\
\hline
\end{tabular}

model and the modeling parameters are those derived from identification with the model from simple mechanical tests (oedometer and shearing [4]). The methodology and principle of testing is well supported [11] and [12] for compressible soils.

With Cast3M we choose an imposed displacement loading which consists in creating a point field.

In OPTI DIM3, the type of elements chosen here is Cube 8 nodes (CUB8) allowing the use of the "VOLU" operator. The global mesh includes 3437 nodes and of 5080 elements cubic cub8. The different steps A, B, C and D of the our oedometer cell are presented in Figure 5.

At the end of the calculation, objects of types MCHAML (element fields) and CHPOINT (point fields) (constraints and displacements) are grouped together in a table. From this table, we can calculate the maximum and minimum principal stresses using the PRIN operator (Figure 6).

From these same stress data stored in the table, we calculate the stress invariants I1 and J2 using the INVA operator which in turn will allow us to calculate the mean $(p=\mathrm{I} 1 / 3)$ and deviation $(q=\sqrt{3} \mathrm{~J} 2)$ stresses. The plasticity criterion (Equation (1)):

$$
f=q^{2}+M^{2}\left(p^{2}-p p_{c r}\right) .
$$

Can thus be traced and stress states with elastic or plastic behaviour can be traced (Figure 7).

The implementation of the Cam Clay model in Cast3M with a single load surface did not allow to take into account strain-hardening in a single calculation. As a result, two separate calculations are made, each with a chosen pre-consolidation pressure.

The strain-hardening of the material is noticeable by a decrease in the plastic zone (Figure 7(b)) due to an increase in the elastic behavior zone (negative criterion), because the pre-consolidation pressure has a higher value in the second calculation. 


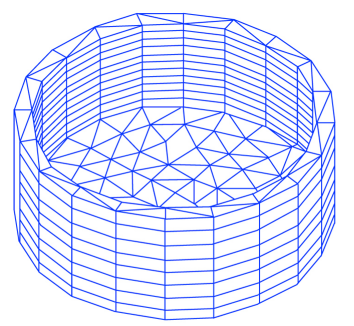

(a)

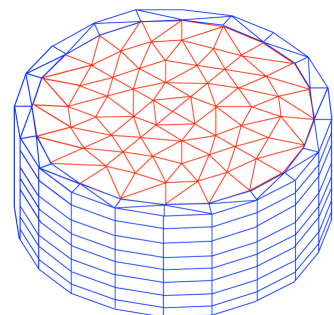

(c)

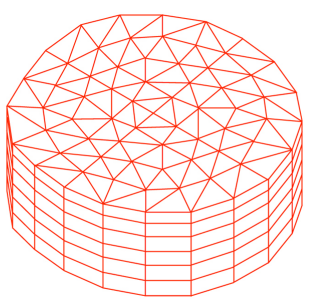

(b)

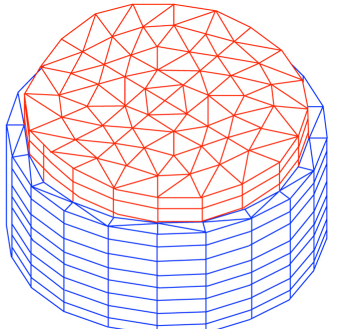

(d)

Figure 5. Mesh of the oedometer cell (a), material (b), cell + material (c), cell + material + piston (d).

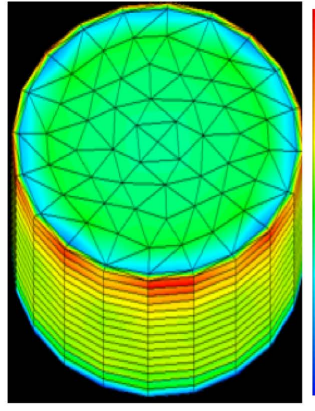

(a)

$1.0010^{5}$
$4.7010^{4}$
$-6.2410^{3}$
$-5.9510^{4}$
$-1.1310^{5}$
$-1.6610^{5}$
$-2.1910^{5}$
$-2.5510^{5}$

Figure 6. Minor (a) and maximum (b) principal stress diagrams for the Sindia sample. (a) Sigma_33; (b) Sigma_11.

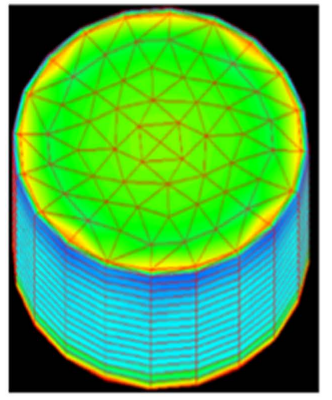

(a)

\begin{abstract}
$2.78 \times 10^{10}$
$2.26 \times 10^{10}$

$1.74 \times 10^{10}$

$1.23 \times 10^{10}$

$7.09 \times 10^{9}$

$1.92 \times 10^{9}$

$-3.24 \times 10^{9}$

$-6.69 \times 10^{9}$
\end{abstract}

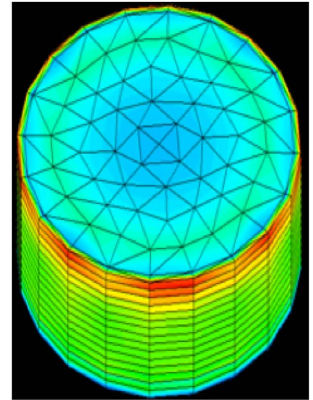

$1.6310^{5}$ $1.1610^{5}$ $6.9010^{4}$ $2.2210^{4}$ $-2.4510^{4}$ $-7.1310^{4}$ $-1.1810^{5}$ $-1.4910^{5}$

Figure 7. Plasticity criteria for Pcon1 (a) and Pcon2 (b) for the Sindia sample.

For Sindia laterite, the maximum principal isostresses range from $-1.62 \times 10^{5}$ $\mathrm{Pa}$ to $1.65 \times 10^{5} \mathrm{~Pa}$, while the minimum principal isostresses are between $-2.7 \times$ $10^{5} \mathrm{~Pa}$ and $1.03 \times 10^{5} \mathrm{~Pa}$ (Figure 6).

Figure 7 shows the elasto-plastic stress state of the Sindia lateritic material. 
The first limit state point which is Pcon $1=22.11 \mathrm{kPa}$ determined from the oedometric results [4] leads to the plasticity criterion (Figure $7(\mathrm{a})$ ) with $2.02 \times 10^{8}$ $\mathrm{Pa}$ as the plastic value closest to zero and $2.7 \times 10^{10} \mathrm{~Pa}$ as the largest. The values for which $f\left(p, q, p_{c r}\right)<0$ are between $-6.69 \times 10^{9} \mathrm{~Pa}$ and $-1.52 \times 10^{9} \mathrm{~Pa}$. For this stress range, the behavior of the material is purely elastic. For the criterion (Figure $7(\mathrm{~b})$ ) corresponding to the second preconsolidation pressure Pcon2 = $53.69 \mathrm{kPa}$ [4], a decrease in the range of plastic behavior is observed due to the strain-hardening of the material. The value of the smallest plastic stress decreases from $2.02 \times 108 \mathrm{~Pa}$ to $2.33 \times 10^{9} \mathrm{~Pa}$. Below this value, the behavior remains elastic.

For the Keur Samba laterite sample, the calculations give maximum principal stresses between $-2.31 \times 10^{5} \mathrm{~Pa}$ and $2.53 \times 10^{5} \mathrm{~Pa}$ (Figure $8(\mathrm{~b})$ ) and minimum principal stresses of values between $-3.46 \times 10^{5} \mathrm{~Pa}$ and $1.62 \times 10^{5} \mathrm{~Pa}$ (Figure $8(\mathrm{a})$ ). This is an important range of values when compared with the Sindia sample.

The first pre-consolidation pressure Pcon $1=24.02 \mathrm{kPa}$ and the second Pcon2 $=53.83 \mathrm{kPa}$ [4] give the plasticity criteria $f\left(p, q, p_{c r}\right)$ in Figure 9 . The range of elastic behavior $(f<0)$ varies between $-1.63 \times 10^{10} \mathrm{~Pa}$ and $-1.91 \times 10^{9} \mathrm{~Pa}$ for Pcon 1 and between $-1.7 \times 10^{10} \mathrm{~Pa}$ and $-4.61 \times 10^{9} \mathrm{~Pa}$ for Pcon2. Naturally, the elasticity increases with the pre-consolidation pressure. The material collapses and increases its reversibility zone.

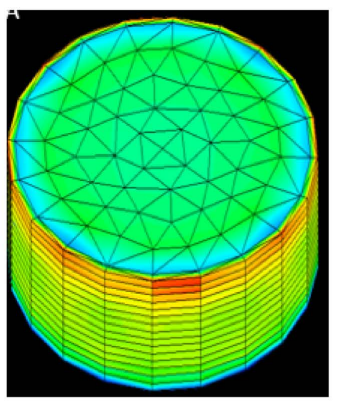

(a)

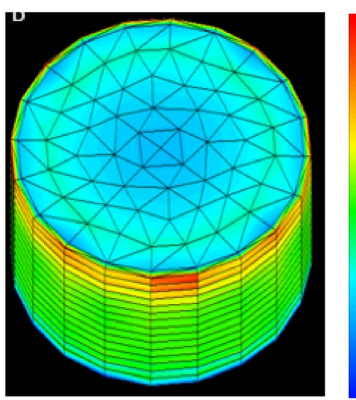

$2.4910^{5}$

$1.8110^{5}$

$5.1410^{5}$

$4.5910^{4}$

$-2.1810^{4}$

$-8.9510^{4}$

$-1.5710^{5}$

$-2.0210^{5}$

(b)

Figure 8. Minor (a) and maximum (b) principal stress diagrams for the Keur Samba sample. (a) Sigma_33; (b) Sigma_11.

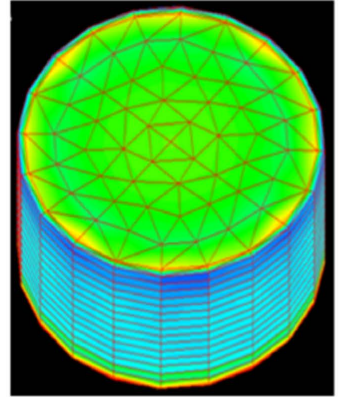

(a)

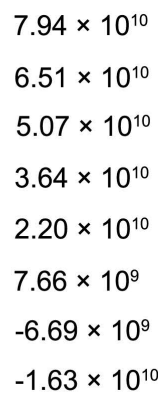

$-1.63 \times 10^{10}$

Figure 9. Plasticity criteria for Pcon1 (a) and Pcon2 (b) for the Keur Samba sample.

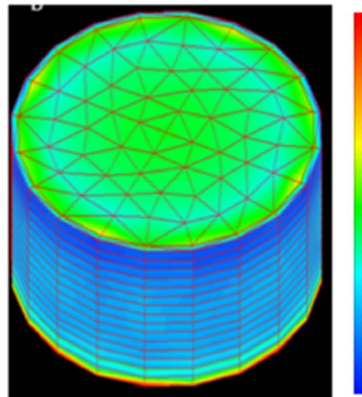

$1.08 \times 10^{11}$

$8.92 \times 10^{10}$

$7.05 \times 10^{10}$

$5.18 \times 10^{10}$

$3.30 \times 10^{10}$

$1.42 \times 10^{10}$

$-4.61 \times 10^{9}$

$-1.71 \times 10^{10}$

(b) 


\section{Conclusions}

In this publication, we have been able to establish the continuation of the work begun, which consisted in identifying tropical soils with complex behavioral models based on simple mechanical tests [4]. However, in this article, we have verified the methodology of our previous study by simulating the laboratory tests using the finite elements software OptumG2. This verification has allowed us to believe that the tests were carried out correctly and that the methodology was appropriate.

Finally, a finite element calculation using the Cast $3 \mathrm{M}$ software, allowed the application of the modified cam clay model on lateritic samples which were, in fact, identified with this model in the previous study [4] [13]. This allowed us to interpret an elastoplastic behaviour based on the writing of the plasticity criterion. The knowledge of the stress invariants, stored in the Cast3M table after the calculations, allows us to determine the spherical pressure and deviatoric stresses. This leads to plotting the load surfaces.

This is a result that we consider interesting because it allows us to know all the behaviours of the studied material by applying the mathematical modelling that the modified cam clay model includes; namely the elastoplastic deformations (volumetric and deviatoric), the contracting and expanding behaviour as well as the level of stresses on the critical state line as well as their assumption in the dimensioning. This will probably be the subject of the next publication.

\section{Acknowledgements}

I deeply thank the Laboratory of Mechanics and Modelling of the UFR Sciences de l'Ingénieur of the University of Thiés (Sénégal) and the Laboratory of D'Alembert of the Sorbonne University (ex Pierre et Marie Curie) of Paris (France).

\section{Conflicts of Interest}

The authors declare no conflicts of interest regarding the publication of this paper.

\section{References}

[1] Roscoe, K.H., Schofield, A.N. and Wroth, C.P. (1958) On the Yielding of Soils. Géotechnique, 8, 22-53. http://doi.org/10.1680/geot.1958.8.1.22

[2] Schofield, A. and Wroth, P. (1968) Critical State Soil Mechanics. Lecturers in Engineering at Cambridge University. http://www.civ.eng.cam.ac.uk/geotech new/publications/schofield8wroth81968.pdf

[3] Tavenas, F. and Leroueil, S. (1977) Effects of Stresses and Time on Yield of Clay. Proceedings 9 th Int. Conf. on Soil Mech. and Found. Eng., Tokyo, Vol. 1, 319-326.

[4] Ndiaye, C. and Berthaud, Y. (2018) Identification of a Cam Clay Model through Shear-Box and Oedometer Tests. Application to Lateritical Soils from Senegal (West Africa). Geomaterials, 8, 1-13. https://doi.org/10.4236/gm.2018.81001

[5] Fall, M. (1993) Identification and Mechanical Characterization of Lateritic Gravels 
from Senegal: Application to the Road Domain. Doctoral Thesis of the I.N.P.L (National Polytechnical Institut of Lorraine/France) in Civil Engineering, 240 p.

[6] Fall, M., Tisot, J.P. and Cisse, I.K. (1995) Mechanical Behavior at the Casagrande Shear Apparatus of Three Lateritic Gravels from Western Senegal. Bulletin of the International Association of Engineering Geology, 52, 59-73.

https://doi.org/10.1007/BF02602682

[7] OptumG2 Materials Manual (2016).

[8] Castem. http://www-cast3m.cea.fr

[9] El Dine, B.S. (2007) Study of the Mechanical Behavior of Coarse Matrix Soils. Planète et Univers [physics]. Ecole-des-Ponts ParisTech, French.

[10] Thi, D.V. (2017) Numerical and Analytical Modeling of Drying Cracking in Clay Soils. Civil Engineering. Paris-Est University, French.

[11] Berthaud, Y., De Buhan, P. and Schmitt, N. (2013) Aide-mémoire de mécanique des sols-Dunod Ed. 2e édition, Dunod Ed./L'Usine Nouvelle, collection Aide-mémoire de l'ingénieur, $320 \mathrm{p}$.

[12] Ndiaye, C., Fall, M., Ndiaye, M., Sangare, D. and Tall, A. (2014) A Review and Update of Analytical and Numerical Solutions of the Terzaghi One-Dimensional Consolidation Equation. Open Journal of Civil Engineering, 4, 274284.

https://doi.org/10.4236/ojce.2014.43023

[13] Ndiaye, C. (2018) Application of the Concepts of Limit State and Critical State to Tropical Soils. Doctoral Thesis of the University of Thiès/Senegal in Geotechnics, $177 \mathrm{p}$. 